\title{
Chlamydia-related Organisms: Infection in Ruminants and Potential for Zoonotic transmission
}

\author{
Nick Wheelhouse • David Longbottom
}

Published online: 24 January 2015

(C) Springer International Publishing AG 2015

\begin{abstract}
The chlamydiae are a diverse group of obligate intracellular Gram-negative bacteria that are known to infect a wide variety of host species and are responsible for a wide range of diseases in animals and man. Studies of human disease first provided evidence for the disease-causing potential of Chlamydia-related bacteria, however there is now increasing evidence that a number of these organisms may also be the causative agents for a number of pathogenic conditions of ruminants that had previously remained undiagnosed. The aim of this review is to draw together the evidence for the role of the newly emerging chlamydial infections in livestock disease.
\end{abstract}

Keywords Chlamydia · Chlamydia-related organisms · Zoonotic potential

\section{Introduction}

Chlamydiae are a diverse group of obligate intracellular Gram-negative bacteria that infect a wide variety of host species, including vertebrates, arthropods and amoeba. In man, chlamydiae are the leading cause of infectious blindness (trachoma) [1] and sexually-acquired infections [2]. In addition, there is evidence for their roles in a range of conditions including respiratory infections [3], cardiovascular disease [4] and neurodegenerative disorders [5]. Chlamydial infections in

This article is part of the Topical Collection on Bacteriology

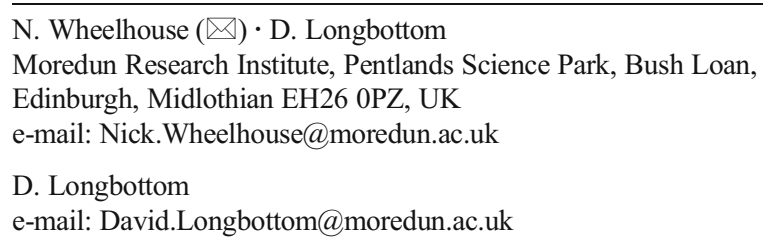

animals are known to be responsible for a range of conditions including abortion, infertility, respiratory disease, enteritis, conjunctivitis and encephalomyelitis [6].

Chlamydial infections in ruminants are a significant cause of economic loss and welfare concern for the agricultural sector worldwide. Currently the most widely investigated chlamydial infections of ruminants are those caused by Chlamydia abortus (C. abortus) and C. pecorum, both of which have been extensively reviewed elsewhere [6]. Chlamydia abortus is the aetiological agent of enzootic abortion of ewes (EAE; also known as ovine enzootic abortion or OEA) the single largest infectious cause of ovine abortion in the UK and Northern Europe. Chlamydia pecorum is considered to play a role in a variety of conditions in both small and large ruminants, including pneumonia, conjunctivitis, polyarthritis, intestinal infections, mastitis, metritis and encephalomyelitis [7], though can often be identified in the faeces of asymptomatic animals. However, more recent investigations have identified other organisms, variously referred to as 'environmental' Chlamydia, 'Chlamydia-like' or Chlamydia-related' organisms, as possible important aetiological agents of disease in ruminant livestock.

\section{Taxonomic Classification}

Chlamydia-related or Chlamydia-like organisms are generic terms for species of obligate intracellular bacteria belonging to the order Chlamydiales. However, these organisms demonstrate significant differences at both a genotypic and phenotypic level resulting in their classification outwith the classical Chlamydiaceae family group (Fig. 1). Initial descriptions of Chlamydia-related organisms resulted from several diverse sources: as organisms identified in free-living amoebae by electron microscopy having developmental cycles similar to those of the Chlamydiaceae $[11,12]$; as a cell culture 


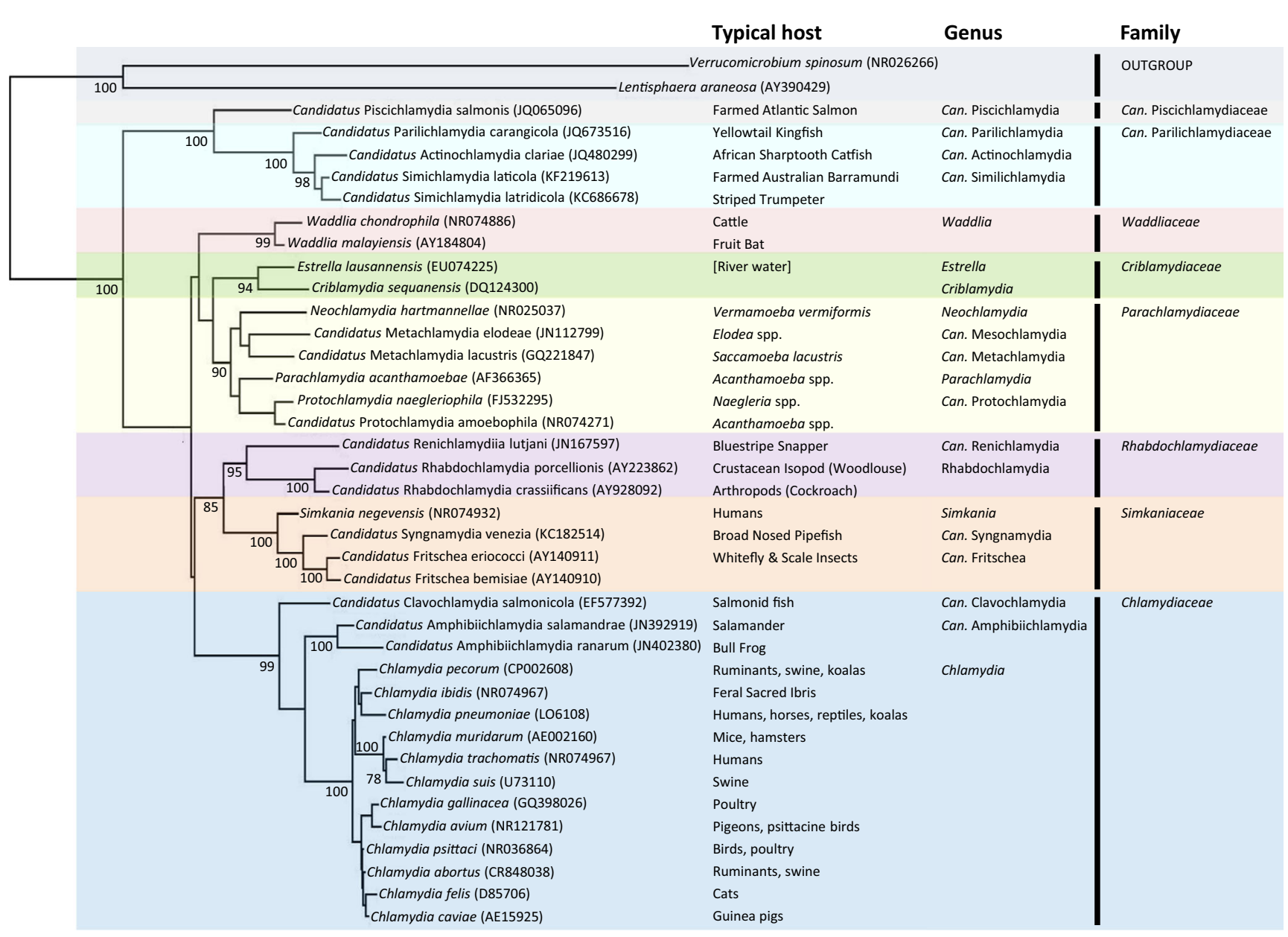

Fig. 1 16S rRNA phylogentic tree depicting families, genera and typical hosts for species of the order Chlamydiales. Phylogenetic trees were constructed by analyses of the 16S rRNA sequences from representative members of order Chlamydiales, plus two outgroup species, Verrucomicrobium spinosum and Lentisphaera araneosa (GenBank database accession numbers are indicated). 16S rRNA sequences were aligned using the Clustal Omega
Multiple Sequence Alignment program available at EMBL-EBI [8]. A maximum likelihood (PhyML) tree was constructed using a GTR substitution model (Gamma-distributed rate model) and 100 bootstrap runs within the TOPALi v2 package [9]. The tree was midpoint rooted and drawn using Dendroscope [10]. Bootstrap support values are given at nodes, values below $70 \%$ are indicated with an asterisk contaminant [13]; and as an organism isolated from a case of bovine abortion [14]. Subsequent comparisons of $16 \mathrm{~S}$ rDNA classified these organisms into the genera Neochlamydia, Parachlamydia, Simkania and Waddlia $[15,16]$. More recent molecular evidence derived from 16S rDNA gene studies has identified a large variety of sequences from a variety of human, animal and environmental sources. The continual discovery of an ever expanding number of Chlamydia-related organisms has resulted in an expansion of the number of families within the Chlamydiales to eight, each one exhibiting an 80-90\% 16S rDNA sequence identity with the Chlamydiaceae (Fig. 1). However, it should be noted that recent phylogenetic analysis of the available data within metagenomic and amplicon databases has suggested even greater diversity within the Chlamydiales with the dramatic figure of 181 putative families being estimated [17•].
In addition to their similarities at a molecular level and despite differences in their host ranges and their resultant pathogenic conditions, all known members of the Chlamydiales share a similar and distinct biphasic developmental cycle. The extracellular, infective version is an electron dense, metabolically less-active form $[18,19]$ known as the elementary body (EB), while the metabolically active, intracellular form, is known as the reticulate body (RB). Upon entry into cells, EBs differentiate into RBs within a vacuole known as an inclusion [20]. The RBs divide by binary fission before undergoing condensation back into EBs prior to release from the host cell by either cellular extrusion or lysis. A further infective form known as a crescent body has also been observed for Parachlamydia acanthamoebae [21], although recent evidence suggests that this may be an observed artefact of the fixation and processing protocol used during sample preparation for transmission electron microscopy [22]. 


\section{Chlamydia-Related Organisms}

Waddliaceae

\section{Identification and Prevalence}

One of the first Chlamydia-related organisms to be successfully isolated was obtained from a case of bovine abortion in the United States in 1986 [14, 23]. The organism (strain designation WSU86-1044) demonstrated significant crossreactivity with sera to Cowdria ruminantium and was initially identified as a Rickettsia [14]. However, further studies revealed the organism to replicate within intracellular vacuoles in a number of different cell types and to have a developmental cycle similar to that of the Chlamydiaceae [24]. Subsequent taxonomic classification by $16 \mathrm{~S}$ rRNA gene analysis placed it within the Chlamydiales and it was named Waddlia chondrophila [16]. This remained the only direct report of the organism until its identification and isolation from a septic stillborn calf in Germany 16 years later [25]. However, in this subsequent case the organism was identified as a co-infection with the bovine abortifacient apicomplexan parasite Neospora caninum. Serological evidence has provided further indirect evidence for a causative role in abortion following an observed correlation between elevated $W$. chondrophila antibody titres and abortion in cattle [26]. However, there were no further direct reports of the organism in cases of cattle abortion until a recent Swiss study in 2011 identified three cases by real-time PCR, with the presence of the organism being confirmed in two of these cases by immunohistochemistry [27]. Most recently, $W$. chondrophila DNA has also been identified in vaginal swabs obtained from a relatively high number of aborted cattle (12 of 150 animals ( $8 \%)$ ) in North Africa [28].

\section{Immunopathogenesis, Persistence and Immune Response to Infection}

There have been few studies that have investigated the potential pathological effects of $W$. chondrophila infection. Initial in vivo studies demonstrated the organism's ability to induce bovine fetopathy [23]. Furthermore its administration to colostrum-deprived calves and yearling goats was demonstrated to induce transient clinical symptoms, which included fever, leucopoenia and a slower developing but longer lasting anaemia. Recently, in vitro studies have been undertaken to attempt to understand the mechanisms of pathogenesis of $W$. chondrophila infection. The demonstration that $W$. chondrophila is capable of surviving in macrophages has been hypothesised as a mechanism through which the organism may evade the innate immune response to infection [29]. Its ability to survive and persist in endometrial cells and pneumocytes has also been suggested to act as a local reservoir for the organism in the female reproductive tract and lungs [30]. Although the organism has been shown to infect a wide variety of cell types all of these studies have been performed in human cells and cell lines. While initial isolation was performed in bovine turbinate cells $[14,23]$ there were no further published studies in ruminant cells until a recently published study investigated the responses in an ovine placental cell line $[31 \bullet]$. This study demonstrated that the organism not only replicated efficiently within the cells but also stimulated expression of pro-inflammatory chemokines/cytokines, CXCL8, TNF- $\alpha$ and IL- $1 \beta$ in a dose-dependent manner. These responses mirrored those induced by C. abortus in the same cell line [32]. While induction of expression appeared to occur much earlier after infection with $W$. chondrophila, the organism was shown to have a faster developmental cycle of between 36-48 $\mathrm{h}$ in comparison to the 72-96 h cycle of C. abortus [32]. These results suggest that $W$. chondrophila stimulates an innate immune response similar to that of classical Chlamydia. However, pathogenesis studies are required to investigate if these immunopathogenic mechanisms play significant roles in disease progression in vivo.

\section{Parachlamydiaceae}

\section{Disease Potential}

The family Parachlamydiaceae comprises species belonging to the genera Parachlamydia, Neochlamydia and Protochlamydia (Fig. 1). Members of this family are primarily regarded as 'environmental' chlamydiae and in culture have been shown to exhibit only a limited ability to colonise and grow in non-protozoan hosts. However, evidence gained through clinical studies in humans and animals and the use of experimental animal models suggests that at least some members of this family may have the potential to cause disease.

\section{Identification, Prevalence and Pathogenesis}

An initial study in Switzerland in 2007 on 243 bovine abortion samples using a pan-Chlamydiales 16S PCR determined a prevalence rate for Chlamydia-related organisms of $18.3 \%$ [33]. The presence of these organisms within the placental tissues was confirmed by electron microscopy, which revealed inclusions and cocci-shaped bacteria with a distinct appearance resembling that of Chlamydia-related organisms. Additional analysis of these samples using a specific real-time PCR protocol and a Parachlamydia-specific antibody identified the organisms as Parachlamydia [33, 34]. These initial studies highlighted potential parachlamydial involvement in bovine abortion and led to further studies in other countries. Gramnegative intracellular bacteria identified in the trophoblast cells of two bovine abortion placental samples obtained during an ongoing abortion storm in the UK were confirmed as 
Parachlamydia in both samples using molecular and immunohistochemical techniques [35]. A further retrospective study analysing pooled tissues from undiagnosed cases of bovine abortion identified $26 \%$ of the samples as positive for Chlamydia-related organisms, however, in addition to Parachlamydia, Rhabdochlamydia was also identified as associated with bovine abortion for the first time [36]. The high level of detection of 18-26\% in these initial Swiss and UK studies has been confirmed in subsequent studies carried out on placental samples from Scotland by immunohistochemistry [37] and from placental and fetal tissue samples from Ireland by real-time PCR [38]. There is also some evidence to suggest a degree of regional variation in the prevalence of the organism in cases of bovine abortion, with a more recent Swiss study demonstrating a lower apparent prevalence rate of $13.4 \%$ [27] compared with the $18.4 \%$ observed previously within the same country $[28,29]$. However, the results indicated that there was a significant regional difference in prevalence patterns across the country with the majority of Parachlamydia-positive cases observed in western areas. This was in almost complete contrast with cases of $C$. abortus that were mainly identified in eastern and central areas of Switzerland. A lower prevalence rate of $5.3 \%$ for Parachlamydia was observed in a study carried out on Tunisian cattle; however, the study also identified Chlamydia in $4.7 \%$ and W. chondrophila in $8 \%$ of cases, resulting in a total prevalence of $18 \%$ for chlamydial organisms. Interestingly, the Parachlamydia-positive animals were all identified from within the same herd of 1500 animals. However, it should be pointed out that this analysis differed from those previously conducted as it was performed retrospectively on vaginal swabs taken post-abortion rather than directly on clinical tissues [39]. Although direct experimental studies are required to demonstrate a causal role for Parachlamydia infection in bovine abortion, histopathology of placentas associated with parachlamydial infection has revealed colonisation of the placental trophoblasts and pathology typical of bacterial placentitis, which may be sufficient to cause abortion [37].

\section{Infection in Small Ruminants}

Only one published study to date has investigated parachlamydial involvement in cases of reproductive failure in small domestic ruminants [40]. The study performed on ovine and caprine abortion samples from Switzerland could only identify Parachlamydia in two of $211(0.9 \%)$ placental samples, one of these being a mixed infection with $C$. abortus. Conversely, the incidence of $C$. abortus infection in the same sample set was $26.1 \%$, which is consistent with its known role as a major abortifacient of sheep and goats. In the majority of cases of abortion in small ruminants it is unlikely that Parachlamydia would be identified by routine surveillance. Many of these diagnoses are made in the regional laboratories based upon gross pathology and the routine use of staining techniques such as modified Ziehl-Neelsen [41], which could potentially fail to differentiate chlamydial species. Thus, it is highly possible that any involvement of Parachlamydia would be missed.

\section{Parachlamydia Involvement in Other Pathogenic Conditions}

While few studies have been carried out to investigate the possible roles of parachlamydial organisms in diseases of livestock other than reproductive disorders, there is some evidence to suggest that they may play roles in additional pathogenic conditions. Studies that have been performed in human subjects have identified Parachlamydia as a potential respiratory pathogen [42], particularly in children [43], and subjects with community-acquired pneumonia [44]. Similarly, there is some evidence for the potential of Parachlamydia as respiratory pathogens of cattle, as parachlamydial DNA has been identified in lung samples from calves with bovine respiratory disease [45]. Recent experimental evidence has also demonstrated that $P$. acanthamoebae can cause clinical symptoms in conventionally reared calves infected by direct inoculation into the lungs [46•]. The clinical symptoms in this model appeared to be relatively mild and transient though the organism could still be recovered from lung tissue samples up to 9 days post infection. In contrast, a similar dose of C. psittaci in a previous study demonstrated significant effects on the morbidity of calves [47], suggesting that Parachlamydia may be a less pathogenic organism of the respiratory tract of cattle. However, in a mouse model $P$. acanthamoebae in addition to causing pneumonia was found to result in significant levels of mortality and to disseminate to the spleen of the animals [48]. Furthermore, in cattle many cases of respiratory disease are due to the sequential effects of viral infection, for example caused by bovine herpes virus-1, followed by a secondary bacterial infection. Thus, Parachlamydia may be an opportunistic respiratory pathogen in cattle, taking advantage of animals that are already compromised through infection with other microorganisms.

Cases of ovine conjunctivitis caused by chlamydial infections are relatively common, though the causative agent is often identified as C. pecorum. Ocular swabs taken from sheep in Switzerland were found to contain DNA from Parachlamydia and Chlamydia-related organisms [49]. Similarly, conjunctival swabs from wild deer were also shown to be positive for Parachlamydia by real-time PCR [50]. A causal link to disease however remains to be established especially as DNA from these organisms was also recovered from the swabs of asymptomatic animals. However, parachlamydial DNA has also been identified in ocular conditions in a variety of other animal species, including guinea pigs [51] and cats [52], so it is interesting to speculate a causative role for these organisms in ovine conjunctivitis. 


\section{Other Chlamydia-related Organisms}

The order Chlamydiales comprises a huge and ever expanding number of bacterial species, of which little is known for many of the members [17•] and the vast majority of the chlamydial sequences obtained from human and animal conditions still remain unclassified. However, it is uncertain whether this expansive collection of unclassified sequences represents a diverse number of potential newly identified chlamydial pathogens or whether many of them belong to currently recognised families, genera or even species. For example, the sheep conjunctival uncultured chlamydiales clone (FJ160739) [49] can be demonstrated to exhibit $99 \%$ similarity to sequences within the Parachlamydiaceae [53]. However studies of Chlamydia-related organisms in ruminants remain limited and in the majority of these cases the observed sequences can be assigned to members of the Parachlamydiaceae or occasionally the Waddliaceae. In addition to these studies however there is some evidence for species of the Rhabdochlamydiaceae in ruminant disease.

The Rhabdochlamydiaceae (Fig. 1) were originally identified as parasites of arthropods: Rhabdochlamydia porcellionis (R. porcellionis), which was first identified as infecting the hepatopancreatic cells of Porcellio scaber (more commonly known as the woodlouse) [54], and $R$. crassificans, which was found to cause abdominal swelling in the cockroach, Blatta orientalis [55]. Recently, a third potential member of the Rhabdochlamydiaceae has been identified in both the spleen and kidney of the blue-striped snapper, Renichlamydia lutjani [56]. Phylogenetic analysis of available genomic data has suggested that the Rhabdochlamydiaceae may comprise the largest single family within the Chlamydiae [17•]. However, despite the growing number of studies investigating the roles of chlamydial organisms with abortion in both large and small ruminants there has been only one published report of Rhabdochlamydia associated with animal disease [36]. This study, which investigated the prevalence of Chlamydia in pooled bovine fetal tissue samples, identified 16S rDNA sequences that clustered within the Rhabdochlamydiaceae in $6 \%$ of the abortion samples analysed. However, their role as a causative agent of bovine abortion remains unconfirmed, though no other known pathogens could be identified in these samples. This is an area that requires further investigation to determine any potential causal role.

\section{Potential Modes of Transmission}

Chlamydia-related organisms have been identified from a variety of environmental, animal and human sources. While many studies have been performed on tissue/clinical samples using molecular analyses based upon 16S rDNA sequences, the organisms are also often identified through amoebal co- culture methodologies. Parachlamydia were initially described as intracellular endosymbionts of Acanthamoeba strains isolated from human nasal mucosa [57]. Subsequent analyses have identified Chlamydia-related organisms in amoeba derived from diverse sources, including human cornea, soil, sewage sludge [58], river water [59] and in a water treatment plant [60]. The resistance of these organisms to digestion by amoeba has been hypothesised as providing a potential aquatic reservoir to aid their spread, which is supported by numerous studies that have successfully isolated Parachlamydia [61, 62] from amoeba. However, there is some evidence that these organisms may be capable of survival in the absence of a host, under certain circumstances, as suggested by a recent study demonstrating a greater correlation between the presence of Acanthamoeba and $P$. acanthamoebae in a hospital setting on swabs obtained from the dry floor than those obtained from the moist environment [63]. The same study demonstrated that the P. acanthamoebae could remain viable (although not replicating) for a minimum of 28 days in culture medium, without the presence of a host. The potential of an aquatic source for the transmission of $P$. acanthamoebae was recently investigated following the analysis of cattle drinking water from an ongoing abortion storm [53], where P. acanthamoebae had been demonstrated in abortion material from two of the cases submitted for diagnosis. The drinking water of the cattle, but not the original water source was found to contain 16S rDNA for several Chlamydia-related organisms, including a sequence identical to one isolated from one of the Parachlamydia positive abortion cases. While only DNA was analysed, this study highlighted the potential for contaminated water as a vector for transmission between animals. The source of this contamination was speculated to be via nasal or ocular secretions from infected animals. Support for this theory comes from another study where ocular swab samples from both sheep and wild deer have been demonstrated to contain parachlamydial DNA. Another possible source of transmission is the faecal-oral route and while this has not been specifically demonstrated in domestic ruminant species, a high proportion of faecal samples obtained from wild deer have been shown to contain parachlamydial DNA [50].

Environmental investigations have identified Waddlia DNA in well-water obtained from agricultural land [64] and following metagenomic analysis of microbial soil communities [65]. As these were molecular studies it is unknown whether viable organisms were present. However, given their obligate intracellular lifecycle, it is highly likely that the organism would be identified in a host within these environmental niches if they were viable. Indeed, Waddlia chondrophila has been shown to be capable of colonising and replicating in a wide-variety of potential host species, ranging from amoeba [66] to ticks [23] that may act as potential environmental vectors for transmission to both humans and ruminants. 
A further potential route of infection is via sexual transmission as Chlamydia-related $16 \mathrm{~S}$ rDNA sequences have also been detected in the semen of bulls and rams [67]. While the significance of these observations remains unclear, this does suggest the potential for a venereal route of transmission for these organisms, which is worthy of further study.

\section{Diagnosis}

Diagnostic samples are not routinely analysed for the presence of Chlamydia-related organisms. In abortion cases, Parachlamydia may be observed in placental trophoblast cells following haematoxylin and eosin staining of formalin-fixed tissue sections [37]. The presence of organisms is often associated with a purulent and/or necrotising placentitis very similar to that observed for other Gram-negative intracellular bacteria, such as C. abortus and so without the use of specific diagnostic tools could be easily mis-diagnosed. Although specific polyclonal antibodies raised against whole organisms have been successfully used to detect Parachlamydia [27, 33, 34, 37] and Waddlia [27] species in ruminant abortion samples, limitations have been reported for some of these reagents [37]. However, at present, these reagents remain the most effective tools for demonstrating the presence of the organism in lesions within target tissues.

As previously mentioned, most studies investigating the presence of Chlamydia-related organisms have relied upon the use of molecular techniques. The organisms can be identified using genus-specific conventional PCR assays targeting highly conserved genes, such as the $16 \mathrm{~S}$ ribosomal RNA gene, followed by direct DNA sequencing [68, 69]. In addition, more specific family and species-specific real-time PCRs have also been developed for Parachlamydiaceae spp. [70], Rhabdochlamydiaceae spp. [43] and W. chondrophila [28, 71]. However, most recently a highly sensitive and quantifiable genus-specific real-time PCR protocol, which is compatible with direct sequencing, has been developed [72]. This has been successfully used in recent studies on ruminants [38, 39].

While molecular and immunohistochemical methods are useful tools to define the presence of organisms in diagnostic and research samples, it is really in combination that they demonstrate their true value in forming an accurate diagnosis. However, in many abortion cases this is not possible, principally due to the failure to submit a placental tissue sample or because of the poor quality of the sample (due to contamination or autolysis) received in the laboratory [41]. Thus, for many sample types, such as those obtained as dry swabs or frozen tissues, DNA analysis may be the only tool that we have at our disposal to investigate the presence of an infective organism but may not be enough to form a definitive diagnosis. Only with the submission of appropriate samples under the required conditions for processing will accurate diagnoses be achievable.

\section{Zoonotic Transmission}

While the purpose of this review is to highlight evidence for Chlamydia-related organisms to cause disease in ruminants, many of these organisms have also been associated with pathogenic conditions in humans. Thus, the zoonotic potential of these organisms should also be considered.

It has been suggested that there is a correlation between increased $W$. chondrophila antibody titres and recurrent pregnancy failure in women [73] and recently the organism has been identified in human placentas obtained following miscarriages [74]. Additionally, $W$. chondrophila DNA has been isolated from samples obtained from the respiratory tract of patients with pneumonia [75] and nasopharyngeal aspirates of children with bronchiolitis [71], indicating the organism may play a role in human respiratory disease.

While the evidence for a disease causing role in livestock is relatively new, more extensive work has been carried out to understand the role of Parachlamydiaceae in human disease. Parachlamydia acanthamoebae (P. acanthamoebae) is considered an emerging agent of pneumonia in humans [42]. Parachlamydial DNA has been identified in a variety of lung conditions, including hospitalised neonates with lung complications [43] and in children suffering from bronchiolitis [70], while exposure to the organism has been demonstrated serologically in adults with community-acquired pneumonia [76]. However further clinical studies are still required to establish with certainty the lung-disease causing potential of Parachlamydia.

In humans, Rhabdochlamydia is also a suspected cause of pneumonia [42]. An original study identified two Rhabdochlamydia-related DNA sequences in $1 \%$ of samples obtained from human patients with respiratory disease; however, other potential respiratory pathogens were also identified in these samples [75]. More recently rhabdochlamydial DNA was detected in 16 of 136 samples obtained from patients with suspected respiratory conditions in Finland [77]. In addition, rhabdochlamydial and parachlamydial DNA has also been identified in the lung secretions of hospitalised neonates with its presence associated with complications and extended periods of hospitalisation [43].

While the direct zoonotic transmission of classical chlamydial species including $C$. abortus and $C$. psittaci is well documented [6], the evidence for transmission of the newly emerging Chlamydia-related infections between animals and man remain limited to a few observational studies. Evidence of maternal-fetal transmission of $P$. acanthamoebae has been provided in a case of a young woman who was employed in a butcher's shop located in a cattle breeding area of Switzerland [78]. The woman also kept guinea pigs as pets, which are also known to harbour the organism [51], but direct transmission from any of these potential sources of infection was not established. In a further study, Parachlamydia seropositivity was found to be more common in asymptomatic men 
occupationally exposed to farm livestock than those who were not [79]. Interestingly, the same study cohort also demonstrated higher rates of seropositivity against $W$. chondrophila and Criblamydia sequanensis, but cross-reactivity of immunogenic proteins between these two organisms made the true rates of seroconversion to each organism difficult to determine.

\section{Conclusion}

The role of chlamydial organisms in human and animal disease has been recognised for many years. However, in addition to the classic members of the Chlamydiaceae there are now a number of Chlamydia-related species that appear to exhibit a pathogenic potential in ruminants. While few experimental studies to-date have been carried out to demonstrate the pathogenic nature for these organisms in farm livestock, the widespread prevalence and links to pathogenic conditions indicate a potential economic and welfare importance for these organisms to the agricultural industry. Furthermore, while there is no direct evidence of zoonotic transmission between animals and man, the presence of these organisms in diseases of livestock, companion animals and man makes the possibility highly likely and worthy of further investigation.

Acknowledgements The authors would like to acknowledge the funding of Scottish Government Rural and Environment Science and Analytical Services division (RESAS) and through the Biotechnology and Biological Sciences Research Council (BBSRC) and Zoetis Industrial Partnership Award BB/J015083/1.

\section{Compliance with Ethics Guidelines}

Conflict of Interest Statement Dr. Wheelhouse and Dr. Longbottom both received funding from Scottish Government Rural and Environment Science and Analytical Services division (RESAS) and through the Biotechnology and Biological Sciences Research Council (BBSRC) and Zoetis Industrial Partnership Award BB/J015083/1.

Human and Animal Rights and Informed Consent This article contains no studies with human or animal subjects performed by any of the authors.

\section{References}

Papers of particular interest, published recently, have been highlighted as:

- Of Importance

1. $\mathrm{Hu}$ VH, Harding-Esch EM, Burton MJ, Bailey RL, Kadimpeul J, Mabey DC. Epidemiology and control of trachoma: systematic review. Trop Med Int Health. 2010;15:673-91.

2. Carey AJ, Beagley KW. Chlamydia trachomatis, a hidden epidemic: effects on female reproduction and options for treatment. Am J Reprod Immunol. 2010;63:576-86.
3. Lamoth F, Greub G. Fastidious intracellular bacteria as causal agents of community-acquired pneumonia. Expert Rev Anti Infect Ther. 2010;8:775-90.

4. Watson C, Alp NJ. Role of Chlamydia pneumoniae in atherosclerosis. Clin Sci (Lond). 2008;114:509-31.

5. Contini C, Seraceni S, Cultrera R, Castellazzi M, Granieri E, Fainardi E. Chlamydophila pneumoniae infection and its role in neurological disorders. Interdiscip Perspect Infect Dis. 2010;273573.

6. Longbottom D, Coulter LJ. Animal chlamydioses and zoonotic implications. J Comp Pathol. 2003;128:217-44.

7. Storz J. Overview of animal diseases induced by chlamydial infections. In: Barron AL, editor. Microbiology of Chlamydia. Boca Raton, Florida: CRC Press; 1988. p. 167-92.

8. Sievers F, Wilm A, Dineen D, Gibson TJ, Karplus K, Li W, et al. Fast, scalable generation of high-quality protein multiple sequence alignments using Clustal Omega. Mol Syst Biol. 2011;7:539. doi: 10.1038/msb.2011.75.

9. Milne I, Lindner D, Bayer M, Husmeier D, McGuire G, Marshall $\mathrm{DF}$, et al. TOPALi v2: a rich graphical interface for evolutionary analyses of multiple alignments on HPC clusters and multi-core desktops. Bioinformatics. 2009;25:126-7.

10. Huson DH, Scornavacca C. Dendroscope 3: an interactive tool for rooted phylogenetic trees and networks. Syst Biol. 2012;61: 1061-7.

11. Fritsche TR, Gautom RK, Seyedirashti S, Bergeron DL, Lindquist TD. Occurrence of bacteria endosymbionts in Acanthamoeba spp. isolated from corneal and environmental specimens and contact lenses. J Clin Microbiol. 1993;31:1122-6.

12. Michel R, Hauroder-Philippczyk B, Muller K-D, Weishaar I. Acanthamoeba from human nasal mucosa infected with an obligate intracellular parasite. Eur J Protistol. 1994;30:104-10.

13. Kahane S, Gonen R, Sayada C, Elion J, Friedman MG. Description and partial characterization of a new Chlamydia-like microorganism. FEMS Microbiol Lett. 1993;109:329-33.

14. Dilbeck PM, Evermann JF, Crawford TB, Ward ACS, Leathers CW, Holland CJ, et al. Isolation of a previously undescribed Rickettsia from an aborted bovine fetus. J Clin Microbiol. 1990;28:814-6.

15. Everett KDE, Bush RM, Andersen AA. Emended description of the order Chlamydiales, proposal of Parachlamydiaceae fam. nov. and Simkaniaceae fam. nov., each containing one monotypic genus, revised taxonomy of the family Chlamydiaceae, including a new genus and five new species, and standards for the identification of organisms. Int J Syst Bacteriol. 1999;49:415-40.

16. Rurangirwa FR, Dilbeck PM, Crawford TB, McGuire TC, McElwain TF. Analysis of the 16S rRNA gene of micro-organism WSU 86-1044 from an aborted bovine foetus reveals that it is a member of the order Chlamydiales: proposal of Waddliaceae fam. nov., Waddlia chondrophila gen. nov., sp. nov. Int J Syst Bacteriol. 1999;49:577-81.

17. Lagkouvardos I, Weinmaier T, Lauro FM, Cavicchioli R, Rattei T, Horn M. Integrating metagenomic and amplicon databases to resolve the phylogenetic and ecological diversity of the Chlamydiae. ISME J. 2014;8:115-25. Expansion of our knowledge on the diversity of chlamydial species.

18. Omsland A, Sager J, Nair V, Sturdevant DE, Hackstadt T. Developmental stage-specific metabolic and transcriptional activity of Chlamydia trachomatis in an axenic medium. Proc Natl Acad Sci U S A. 2012;109:19781-5. doi:10.1073/pnas.1212831109.

19. Sixt BS, Siegl A, Müller C, Watzka M, Wultsch A, Tziotis D, et al. Metabolic features of Protochlamydia amoebophila elementary bodies-a link between activity and infectivity in Chlamydiae. PLoS Pathog. 2013;9:e1003553. doi:10.1371/journal.ppat. 1003553.

20. Abdelrahman YM, Belland RJ. The chlamydial developmental cycle. FEMS Microbiol Rev. 2005;29:949-59. 
21. Greub G, Raoult D. Crescent bodies of Parachlamydia acanthamoeba and its life cycle within Acanthamoeba polyphaga: an electron micrograph study. Appl Environ Microbiol. 2002;68:3076-84.

22. Pilhofer M, Aistleitner K, Ladinsky MS, Konig L, Horn M, Jensen GJ. Architecture and host interface of environmental chlamydiae revealed by electron cryotomography. Environ Microbiol. 2014;16:417-29.

23. Crawford TB, Dilbeck PM, Kocan KM, Stiller D, Evermann JF, Kramer JW, McGuire TC. Preliminary studies on a new Rickettsiaceae from an aborted bovine fetus. Proceedings of the 8th Conference on Veterinary Hemoparasite Disease 1989. pp121-127.

24. Kocan KM, Crawford TR, Dilbeck PM, Evermann JF, McGuire TC. Development of a Rickettsia isolated from an aborted bovine fetus. J Bacteriol. 1990;172:5949-55.

25. Henning K, Schares G, Granzow H, Polster U, Hartmann M, Hotzel $\mathrm{H}$, et al. Neospora caninum and Waddlia chondrophila strain 2032/99 in a septic stillborn calf. Vet Microbiol. 2002;85:285-92.

26. Dilbeck-Robertson P, McAllister MM, Bradway D, Evermann JF. Results of a new serologic test suggest an association of Waddlia chondrophila with bovine abortion. J Vet Diagn Invest. 2003;15: 568-9.

27. Blumer S, Greub G, Waldvogel A, Hassig M, Thoma R, Tschuor A, et al. Waddlia, Parachlamydia and Chlamydiaceae in bovine abortion. Vet Microbiol. 2011;152:385-93. doi:10.1016/j.vetmic.2011. 05.024.

28. Barkallah M, Fendri I, Dhieb A, Gharbi Y, Greub G, Gdoura R. First detection of Waddlia chondrophila in Africa using SYBR Green real-time PCR on veterinary samples. Vet Microbiol. 2013;164:101-7.

29. Goy G, Croxatto A, Greub G. Waddlia chondrophila enters and multiplies within human macrophages. Microbes Infect. 2008;10: 556-62.

30. Kebbi-Beghdadi C, Cisse O, Greub G. Permissivity of Vero cells, human pneumocytes and human endometrial cells to Waddlia chondrophila. Microbes Infect. 2011;13:566-74.

31. Wheelhouse N, Coyle C, Barlow PG, Mitchell S, Greub G, Baszler T, et al. Waddlia chondrophila infects and multiplies in ovine trophoblast cells stimulating an inflammatory immune response. PLoS One. 2014;9:e102386. doi:10.1371/journal.pone. 0102386. Demonstration of growth of W.chondrophila in ruminant epithelial cells and an inflammatory response similar to chlamydial infection.

32. Wheelhouse N, Wattegedera S, Stanton J, Maley S, Watson D, Jepson C, et al. Ovine trophoblast is a primary source of TNFalpha during Chlamydophila abortus infection. J Reprod Immunol. 2009;80:49-56.

33. Borel N, Ruhl S, Casson N, Kaiser C, Pospischil A, Greub G. Parachlamydia spp. and related Chlamydia-like organisms and bovine abortion. Emerg Infect Dis. 2007;13:1904-7.

34. Ruhl S, Casson N, Kaiser C, Thoma R, Pospischil A, Greub G, et al. Evidence for Parachlamydia in bovine abortion. Vet Microbiol. 2009;135:169-74.

35. Deuchande R, Gidlow J, Caldow G, Baily J, Longbottom D, Wheelhouse N, et al. Parachlamydia involvement in bovine abortions in a beef herd in Scotland. Vet Rec. 2010;166:598-9.

36. Wheelhouse N, Katzer F, Wright F, Longbottom D. Novel Chlamydialike organisms as cause of bovine abortions. UK Emerg Infect Dis. 2010;16:1323-4.

37. Wheelhouse N, Howie F, Gidlow J, Greub G, Dagleish M, Longbottom D. Involvement of Parachlamydia in bovine abortions in Scotland. Vet J. 2012;193:586-8.

38. Wheelhouse N, Longbottom D, O'Donovan J. Chlamydia in cases of bovine abortion in Ireland. Vet Rec. 2014;174:560-1.

39. Barkallah M, Gharbi Y, Hassena AB, Slima AB, Mallek Z, Gautier $M$, et al. Survey of infectious etiologies of bovine abortion during mid- to late gestation in dairy herds. PLoS One. 2014;9:e91549. doi:10.1371/journal.pone.0091549.

40. Ruhl S, Goy G, Casson N, Thoma R, Pospischil A, Greub G, et al. Parachlamydia acanthamoebae infection and abortion in small ruminants. Emerg Infect Dis. 2008;14:1966-8.

41. Borel N, Frey CF, Gottstein B, Hilbe M, Pospischil A, Franzoso $\mathrm{FD}$, et al. Laboratory diagnosis of ruminant abortion in Europe. Vet J. 2014;200:218-29. doi:10.1016/j.tvj1.2014.03.015.

42. Greub G. Parachlamydia acanthamoebae, an emerging agent of pneumonia. Clin Microbiol Infect. 2009;15:18-28.

43. Lamoth F, Aeby S, Schneider A, Jaton-Ogay K, Vaudaux B, Greub G. Parachlamydia and Rhabdochlamydia in premature neonates. Emerg Infect Dis. 2009;15:2072-5.

44. Marrie TJ, Peeling RW, Reid T, De Carolis E. Chlamydia species as a cause of community-acquired pneumonia in Canada. Eur Respir J. 2003;21:779-84.

45. Wheelhouse N, Longbottom D, Willoughby K. Chlamydia in cases of cattle pneumonia in Scotland. Vet Rec. 2013;172:110.

46. Lohr M, Prohl A, Ostermann C, Liebler-Tenorio E, Schroedl W, Aeby $\mathrm{S}$, et al. Bovine model of a respiratory Parachlamydia acanthamoebae infection. Pathog Dis. 2014. doi:10.1111/2049-632X.12201. First large animal model of infection with a Chlamydia-related organism.

47. Ostermann C, Schroedl W, Schubert E, Sachse K, Reinhold P. Dose-dependent effects of Chlamydia psittaci infection on pulmonary gas exchange, innate immunity and acute-phase reaction in a bovine respiratory model. Vet J. 2013;196:351-9.

48. Casson N, Entenza JM, Borel N, Pospischil A, Greub G. Murine model of pneumonia caused by Parachlamydia acanthamoebae. Microb Pathog. 2008;45:92-7.

49. Polkinghorne A, Borel N, Becker A, Lu ZH, Zimmermann DR, Brugnera E, et al. Molecular evidence for chlamydial infections in the eyes of sheep. Vet Microbiol. 2009;135:142-6. doi:10.1016/j. vetmic.2008.09.034.

50. Regenscheit N, Holzwarth N, Greub G, Aeby S, Pospischil A, Borel N. Deer as a potential wildlife reservoir for Parachlamydia species. Vet J. 2012;193:589-92.

51. Lutz-Wohlgroth L, Becker A, Brugnera E, Huat ZL, Zimmermann $\mathrm{D}$, Grimm F, et al. Chlamydiales in guinea-pigs and their zoonotic potential. J Vet Med A Physiol Pathol Clin Med. 2006;53:185-93.

52. Richter M, Matheis F, Gonczi E, Aeby S, Spiess B. Greub G (2010) Parachlamydia acanthamoebae in domestic cats with and without corneal disease. Vet Ophthalmol. 2010;13:235-7.

53. Wheelhouse N, Sait M, Gidlow J, Deuchande R, Borel N, Baily J, et al. Molecular detection of Chlamydia-like organisms in cattle drinking water. Vet Microbiol. 2011;152:196-9. doi:10.1016/j. vetmic.2011.03.040.

54. Kostanjsek R, Strus J, Drobne D, Avgustin G. 'Candidatus Rhabdochlamydia porcellionis', an intracellular bacterium from the hepatopancreas of the terrestrial isopod Porcellio scaber (Crustacea: Isopoda). Int J Syst Evol Microbiol. 2004;54:543-9.

55. Corsaro D, Thomas V, Goy G, Venditti D, Radek R, Greub G. 'Candidatus Rhabdochlamydia crassificans', an intracellular bacterial pathogen of the cockroach Blatta orientalis (Insecta: Blattodea). Syst Appl Microbiol. 2007;30:221-8.

56. Corsaro D, Work TM. Candidatus Renichlamydia lutjani, a Gramnegative bacterium in internal organs of blue-striped snapper Lutjanus kasmira from Hawaii. Dis Aquat Organ. 2012;98:249-54.

57. Amann R, Springer N, Schonhuber W, Ludwig W, Schmid EN, Muller K-D, et al. Obligate intracellular bacterial parasites of acanthamoebae related to Chlamydia spp. Appl Environ Microbiol. 1997;63:115-21.

58. Fritsche TR, Horn M, Wagner M, Herwig RP, Schleifer K-H, Gautom RK. Phylogenetic diversity among geographically dispersed Chlamydiales endosymbionts recovered from clinical and environmental isolates of Acanthamoeba spp. Appl Environ Microbiol. 2000;66:2613-9. 
59. Thomas V, Casson N, Greub G. Criblamydia sequanensis, a new intracellular Chlamydiales isolated from Seine river water using amoebal co-culture. Environ Microbiol. 2006;8:2125-35.

60. Thomas V, Loret JF, Jousset M, Greub G. Biodiversity of amoebae and amoebae-resisting bacteria in a drinking water treatment plant. Environ Microbiol. 2008;10:2728-45.

61. Corsaro D, Feroldi V, Saucedo G, Ribas F, Loret JF, Greub G. Novel Chlamydiales strains isolated from a water treatment plant. Environ Microbiol. 2009;11:188-200.

62. Corsaro D, Venditti D. Detection of Chlamydiae from freshwater environments by PCR, amoeba coculture and mixed coculture. Res Microbiol. 2009;160:547-52.

63. Fukumoto T, Matsuo J, Hayashi M, Oguri S, Nakamura S, Mizutani Y, et al. Impact of free-living amoebae on presence of Parachlamydia acanthamoebae in the hospital environment and its survival in vitro without requirement for amoebae. J Clin Microbiol. 2010;48:3360-5.

64. Codony F, Fittipaldi M, López E, Morató J, Agustí G. Well water as a possible source of Waddlia chondrophila infections. Microbes Environ. 2012;2:529-32.

65. Shrestha B, Acosta-Martinez V, Cox SB, Green MJ, Li S, Canas-Carrell JE. An evaluation of the impact of multiwalled carbon nanotubes on soil microbial community structure and functioning. J Hazard Mater. 2013;261:188-97. doi:10.1016/j. jhazmat.2013.07.031.

66. Coulon C, Eterpi M, Greub G, Collignon A, McDonnell G, Thomas $\mathrm{V}$. Amoebal host range, host-free survival and disinfection susceptibility of environmental Chlamydiae as compared to Chlamydia trachomatis. FEMS Immunol Med Microbiol. 2012;64:364-73.

67. Teankum K, Pospischil A, Janett F, Brugnera E, Hoelzle LE, Hoelzle K, et al. Prevalence of chlamydiae in semen and genital tracts of bulls, rams and bucks. Theriogenology. 2007;67:303-10.

68. Everett KDE, Andersen AA. Identification of nine species of the Chlamydiaceae using PCR- RFLP. Int J Syst Bacteriol. 1999;49: 803-13.
69. Ossewaarde JM, Meijer A. Molecular evidence for the existence of additional members of the order Chlamydiales. Microbiology. 1999;145:411-7.

70. Casson N, Posfay-Barbe KM, Gervaix A, Greub G. New diagnostic real-time PCR for specific detection of Parachlamydia acanthamoebae DNA in clinical samples. J Clin Microbiol. 2008;46:1491-3.

71. Goy G, Croxatto A, Posfay-Barbe KM, Gervaix A, Greub G. Development of a real-time PCR for the specific detection of Waddlia chondrophila in clinical samples. Eur J Clin Microbiol Infect Dis. 2009;28:1483-6.

72. Lienard J, Croxatto A, Aeby S, Jaton K, Posfay-Barbe K, Gervaix A, et al. Development of a new chlamydiales-specific real-time PCR and its application to respiratory clinical samples. J Clin Microbiol. 2011;49:2637-42.

73. Baud D, Thomas V, Arafa A, Regan L, Greub G. Waddlia chondrophila, a potential agent of human fetal death. Emerg Infect Dis. 2007;13:1239-43.

74. Baud D, Goy G, Osterheld MC, Borel N, Vial Y, Pospischil A, et al. Waddlia chondrophila: From Bovine Abortion to Human Miscarriage. Clin Infect Dis. 2011;52:1469-71.

75. Haider S, Collingro A, Walochnik J, Wagner M, Horn M. Chlamydia-like bacteria in respiratory samples of communityacquired pneumonia patients. FEMS Microbiol Lett. 2008;281: 198-202.

76. Marrie TJ, Raoult D, La SB, Birtles RJ, de Carolis E. Legionellalike and other amoebal pathogens as agents of community-acquired pneumonia. Emerg Infect Dis. 2001;7:1026-9.

77. Niemi S, Greub G, Puolakkainen M. Chlamydia-related bacteria in respiratory samples in Finland. Microbes Infect. 2011;13:824-7.

78. Baud D, Goy G, Gerber S, Vial Y, Hohlfeld P, Greub G. Evidence of maternal-fetal transmission of Parachlamydia acanthamoebae. Emerg Infect Dis. 2009;15:120-1.

79. Baud D, Kebbi C, Kulling JP, Greub G. Seroprevalence of different Chlamydia-like organisms in an asymptomatic population. Clin Microbiol Infect. 2009;15 Suppl 2:213-5. 